Marta Ortiz Canseco

Universidad Autónoma de Madrid

\title{
SENTIDOS Y SENSUALIDAD PERVERTIDA... EROTISMO Y TERROR EN LA REGENTA
}

Si hay una novela que corrobore el indisociable vínculo, para muchos, entre erotismo y terror, esta ha de ser La Regenta, de Leopoldo Alas, Clarín. Aquí, haremos el seguimiento de algunos de los episodios eróticos, con sus respectivos terroríficos corolarios, que inundan la obra. Veremos, de este modo, a través de qué elementos y personajes se manifiestan ambos elementos, erotismo y terror; las escenas más representativas, y los tipos de sexualidad que el autor ha querido retratar en la novela.

\section{Los cinco sentidos en relación con lo erótico}

Comencemos por el modo en que el autor de La Regenta introduce el erotismo a través de los cinco sentidos, tan importantes para entender las sensaciones de los personajes. Aunque, antes, consideremos el interesante punto de vista de Germán Gullón ${ }^{1}$ al hablar de otras claves latentes en el texto que quizá en la época de publicación no se llegaron a apreciar lo suficiente. Destaquemos, por ejemplo, esa inquietante «mirada masculina a la mujer» que abre y cierra la obra; primero, con el Magistral, desde lo alto de la torre; $y$, al final, cuando Celedonio, ese ambiguo personaje que apenas aparece en la trama, se la encuentra en el suelo de la catedral. No podemos obviar todo el simbolismo de la caída que estas dos situaciones - desde arriba, en la torre, y abajo, en el suelo- suponen. Si además recordamos aquello de que «la Regenta cayendo, cayendo era feliz $»^{2}$ queda meridianamente expuesta esta simbología espacial... Pero, como decíamos, la mirada masculina a la mujer es prácticamente lo que sustenta la narración, pues toda Vetusta aparece descrita como un teatro, y la «actriz» de ese teatro va a ser Ana Ozores. Por supuesto, en el público también encontramos miradas femeninas, aunque muchas de ellas quizá se acerquen más a la masculinidad, que se siente irremediablemente atraída por la belleza de Ana -recordemos a Obdulia en la procesión y ese «deseo vago... de... de... ser hombre» (26.826) o las descripciones que hace Visitación de su amiga. Claro que hay otros actores en ese teatro de Vetusta, pero no es a eso a lo que vamos. Resulta significativa esa mirada porque es la que abre toda la carga erótica de la novela y también la que la cierra, como hemos visto. La torre de la catedral, tan repetidamente señalada como símbolo fálico, el catalejo del Magistral, el hecho de que suba allí para observar sus dominios -su Vetusta- y más en concreto a la Regenta... Todo apunta a esa mirada inicial, esa mirada sensual y cargada de erotismo. Una mirada que, al fin y al cabo, responde al afán de impregnar el texto de sensualidad, de hacer presente, de una u otra manera, todo lo relacionado con lo corporal, los sentidos, «ese permanente llenar el texto de olores, de colores y sonidos, para que los sentidos del lector permanezcan a flor de piel» ${ }^{3}$. No hay más que recordar ese fuego

\footnotetext{
${ }^{1}$ Cf. Germán Gullón (2002): «La mirada masculina y la conciencia en La Regenta». En: Leopoldo Alas «Clarín». Actas del simposio internacional. Antonio Vilanova y Adolfo Sotelo Vázquez (eds.). Barcelona: Universitat, p. 329.

2 La Regenta, 28.896. Víctor Fuentes (ed.). Madrid: Akal, 1999. Todas las citas de la novela se harán según este texto. Se indica capítulo y página.

${ }^{3}$ Gullón, op. cit., p. 329.
} 
en las miradas de que ningún personaje se salva, esas «miradas más ardientes» (1.100) de Obdulia hacia el Magistral, o la mirada de don Álvaro cuando Visitación le habla de Anita: «Ya tenía él en sus ojos, casi siempre apagados, las chispas que saltaban de los de Visita» (8.285), o cuando «de Pas vio a la Regenta más hermosa que nunca: en los ojos traía fuego misterioso...» (25.786).

Sírvanos como ejemplo de otros elementos sensuales el ambiente que va creando el personaje de Obdulia Fandiño por donde pasa, y en especial este pasaje en que se recrea la pasión de don Saturnino Bermúdez hacia la seductora de Vetusta: «Pronto las carcajadas de Obdulia Fandiño, frescas, perladas [...] llenaron el ambiente, profanado ya con el olor mundano de que había infestado la sacristía desde el momento de entrar...» (1.99).

Nótese que resalta aquí también otro sentido: el del oído, por esas carcajadas de Obdulia tan sensuales y eróticas, las cuales, junto con su olor, llenan la sacristía de un ambiente totalmente profano, «mundano». Un olor que, por lo demás, vuelve loco a don Saturnino cuando se mezcla con el incienso por ese «juntar así los olores místicos y eróticos» (ibid.) que cree él tan digno del paraíso ${ }^{4}$. En esta frase tenemos ya la clave de la novela en torno a la cual girarán todos los pensamientos de la protagonista: el misticismo y el erotismo. Así pues, la novela es el resultado de la «dicotomía entre el ser pensante y el ser sensual $»^{5}$, representada principalmente por Ana Ozores.

Mas volvamos a la enumeración de los sentidos en relación con lo erótico. Ya hemos mencionado el sentido de la vista, del olfato y del oído. Faltan ahora los más importantes por ser los que más juego dan dentro de la novela: el gusto y el tacto. El primero representado, sobre todo, por la cantidad de comida descrita y degustada en toda la obra, y que, además, viene a ser uno de los principales símbolos de lo erótico. No olvidemos los tres grandes banquetes de que somos testigos: dos en las propiedades de los Vegallana (familia que, por lo demás, puede actuar como mediadora principal de lo erótico) y uno en el Casino, sin contar con el del baile. Todos ellos sirven como escenario de los juegos eróticos que los protagonistas buscan, presencian y practican. Pero existen otros ejemplos más concretos de este sentido del gusto tan típicamente erótico. Recordemos a Visitación -cuyas carcajadas, por otro lado, también son peculiares: «Hablaba mucho, a gritos, con diez carcajadas por cada frase» (8.271) - y ese «siempre hablaba con alguna golosina en la boca» (8.279) tan provocativo, tan tremendamente erótico. Sin mencionar el «iCómetela!» (8.289) que le dirige a su amigo Mesía para que éste ataque a Ana. Pero quizá el mejor ejemplo de las connotaciones sexuales que acarrea este sentido sea el episodio del Magistral en el parque, cuando empieza a juguetear con las rosas: «Cuando el botón ya no tuvo más que las arrugadas e informes [hojas] de dentro, don Fermín se lo metió en la boca y mordió con apetito extraño, con una voluptuosidad refinada de que él no se daba cuenta.» (21.678). Más tarde descubriremos que esta escena es sólo un anticipo de lo que don Fermín hace con las niñas de la catequesis, en un fragmento extremadamente erótico.

Y por último, el tacto -tan sexual de por sí y tan bien interpretado en la novela- se enreda con la vida cotidiana de nuestros personajes. Sírvanos de nuevo como ejemplo el personaje de Visita, a quien «al tocarla la mano cuando no tenía guante, notaba el tacto

\footnotetext{
${ }^{4}$ Más tarde encontramos que a Ana también le seducen estas mezclas, representadas por el Magistral: «No era en estas palabras [...] donde estaba la dulzura inefable que encontraba Ana en lo que oía: era en la voz, en los movimientos, en un olor de incienso espiritual que parecía entrar hasta el alma.» (13.434. La negrita es mía).

${ }^{5}$ Gullón, op. cit., p. 332.
} 
el pringue de alguna golosina que Visita acababa de comer» (8.273). Del mismo modo, y para terminar, vemos a Ana cuando se desnuda para meterse en la cama, un pasaje especialmente erótico: «Dejóse caer de bruces sobre aquella blandura suave con los brazos tendidos. Apoyaba la mejilla en la sábana y tenía los ojos muy abiertos. La deleitaba aquel placer del tacto que corría desde la cintura a las sienes.» (3.131). Una voluptuosidad tan patente que, si bien no se menciona explícitamente la masturbación, sí queda esta camuflada entre los pliegues de esa sábana tan blanca y tan suave para quien quiera imaginárselo. ¿Puede haber algo más intensamente erótico que enseñar lo justo para que el lector dé rienda suelta a la fantasía? El mejor ejemplo lo tenemos, además de en estos pasajes de Ana sola en su cuarto, en el tan codiciado beso entre Mesía y la Regenta, que ocurre en un balcón oscuro y no es descrito por el autor; es decir, así como ellos se esconden de los otros personajes para consumar su amor, también se esconden para el lector, que ha de imaginarse lo que ocurre.

Por otro lado, es interesante notar que estos sentidos tan explotados en función del erotismo se encuentran muchas veces relacionados con los pecados capitales, muy recurrentes en el texto y muy propios de personajes como el Magistral -recordemos su avaricia, su codicia- y muchos otros. No será necesario aclarar que nos referimos a la relación entre el pecado de la gula y ese sentido del gusto de que ya hemos hablado -no hay más que pensar en el atracón de sardinas que se da nuestro querido marqués de Vegallana y que luego vomita antes de empezar a comer-, o la relación entre la lujuria y el sentido del tacto, etc. Pecados capitales condenados por una religión que todos se jactan de seguir fielmente y en los que, sin embargo, hay pocos personajes que no caigan.

\section{Cómo se inserta el terror: personajes y escenas}

No basta con conocer cuáles son los recursos esenciales para introducir el erotismo en el texto. Sabemos ya que lo sensorial es uno de los vehículos más importantes para ello, pero no es suficiente. Hay personajes con gran sensualidad, y ellos son los que introducen frecuentemente no poca carga erótica. Del mismo modo, encontramos también personajes que representan, por antonomasia, lo terrorífico, lo inquietante, lo oscuro. Por ello es interesante descubrir cómo se engarza lo uno y lo otro, el modo en que Clarín lo relaciona.

Intentaré, en consecuencia, sintetizar los procesos en que erotismo y terror van juntos y aquellos en los que erotismo y terror se presuponen. En los ejemplos expuestos hasta aquí, el erotismo se encuentra ligado exclusivamente al campo de los sentidos. Es decir, no siempre que aparecen escenas eróticas han de ir éstas seguidas de otras tantas terroríficas, aunque dicha fórmula sí sea recurrente. Tampoco quiere esto decir que el terror aparezca aislado siempre; lejos de ser así, normalmente aparece ligado a sensaciones, a impresiones que entran directamente por los sentidos, a sentimientos ligados directamente con lo erótico.

Existen, por lo tanto, escenas y personajes que conllevan, con su aparición, una de estas dos sensaciones, o ambas a la vez. Así como hemos visto que Obdulia Fandiño o Visitación Olías de Cuervo podrían representar el erotismo, del mismo modo doña Paula, Petra, doña Petronila, el propio Fermín y en general cualquier personaje que tenga que ver con el clero, representarían el terror. Esta clasificación puede resultar arriesgada y maniquea, en cuanto que no siempre todos estos personajes encarnan el terror; pero, en general, sus figuras van asociadas a ello. Cuando aparecen, un escalofrío estremece al lector, que siente miedo; son personajes que no inspiran precisamente confianza. De entre todos, es doña Paula quien mejor responde a esta sensación de terror, a este terrorismo exclusivo. 
Veamos la descripción de la madre del Magistral, cuando aparece por primera vez, cortándole el paso a Petra: «Tenía la figura cortada a hachazos, vestía como una percha [...] Parecía doña Paula, por traje y rostro, una amortajada.» (11.360). O en lo alto de la escalera, esperando a su hijo: «Dispuesta a estorbarle el paso, allí en medio, tiesa, como un fantasma negro, largo y anguloso [...] Cuando su madre callaba y se ponía parches de sebo, daba a entender que no podía estar más enfadada, que estaba furiosa.» (15.475).

Este «fantasma negro, furioso», esta «amortajada», es uno de los personajes con más carga terrorífica de toda la obra. Sin embargo, nunca va ligado al erotismo, sino que se mantiene en su penumbra, a pesar de que, a veces, se ve rodeada de personajes eróticos o de situaciones turbadoramente sensuales. Véanse, sin ir más lejos, las escenas entre el Magistral y su criada, que no necesitan de mayores comentarios: «Teresina quedó a solas con su amo y mientras le servía agua dejando caer el chorro desde muy alto, suspiró discretamente. De Pas la miró, un poco sorprendido. Estaba muy guapa; parecía una virgen de cera.» (15.476). Sin olvidar, por supuesto, la escena en que, por la mañana, Teresina hace la habitación al Magistral con movimientos no precisamente pudorosos y dejando ver quizá más de lo que un clérigo debería (11.355). Todo ello mientras doña Paula duerme, aunque ya sabemos que es ella quien proporciona las doncellas a don Fermín, todas a su plena disposición.

También Glocester podría responder a esta exclusiva caracterización de lo horrible, de lo perverso. Un personaje capaz de todo con tal de conseguir sus propósitos, envidioso y terrible. He aquí su primera aparición: «Encontraba el Arcediano [...] relación entre aquella manera de $F$ que figuraba su cuerpo y la sagacidad, la astucia, el disimulo, la malicia discreta y hasta el maquiavelismo canónico que era lo que más le importaba.» (2.111).

Este terror exclusivo, sin embargo, no se da en el resto de los personajes asociados con lo terrorífico. Existe siempre cierta ambigüedad, cierta ambivalencia entre terror y erotismo que no deja indiferente al lector. Se manifiesta en los personajes secundarios, y sobre todo en los que llaman la atención por su ambigüedad, es decir, personajes asociados al terror, pero que se ven inmersos en situaciones, provocadas por ellos mismos, que no dejan de ser perversamente eróticas. Son los personajes grotescos, entendiendo grotesco, según Kronik ${ }^{6}$, como la «sensación de incomodidad ante un orden desplazado», una «distorsión de formas más exagerada y problemática que en una simple caricatura». Definición, por lo demás, acertadísima para este tipo de caracteres. Nos referimos, más en concreto, a Celedonio y a doña Petronila. Ambos presentados como repugnantes en un principio, pero actores también de escenas eróticas, en las que por supuesto, no dejan de ser repulsivos.

El Gran Constantino, por ejemplo, aparece por primera vez descrita como «una señora que parecía un fraile» (13.421), que, además, «creíase poco menos que papisa [...] por haber sabido conservar con decoro las tocas de la viudez y por levantar edificios...» (13.444). Muy aborrecida por Ripamilán, pero tratada como una reina por el Magistral, quien, como descubrimos después, la utiliza como celestina y usa su casa para las «confesiones» con la Regenta. A lo largo de la novela aprendemos que se trata de un personaje sucio, rastrero, que actúa de tercera al servicio del Provisor a pesar de su aparente religiosidad; don Fermín la ha educado conforme a sus intereses. Nunca está cuando el

${ }^{6}$ Cf. John W. Kronik (1987): «El beso del sapo: configuraciones grotescas en La Regenta». En: «Clarín» y La Regenta en su tiempo. Actas del simposio internacional. Oviedo: Universidad, p. 518. 
Magistral y Ana hablan en su casa, si llega y les ve se va rápidamente; su dimensión grotesca e inquietante la descubrimos cuando se atreve a besar la frente de Ana: «Fue un beso solemne, apretado, pero frío... Parecía poner allí el sello de una cofradía mojado en hielo.» (18.598). Este elemento grotesco, que encontramos a lo largo de toda la novela, le sirve a Clarín para atacar las estructuras sociales y morales de su época. «La supuesta deformación de las líneas normativas de la realidad es, en el fondo, un fiel reflejo de una realidad deforme por naturaleza. $\rangle^{7}$ Algo que, por otro lado, nos recuerda a los esperpentos de Valle-Inclán y da cuenta de la modernidad de esta novela.

Celedonio es el mejor exponente de esa realidad deformada; ese personaje de quien, al principio de la novela, «se podía adivinar futura y próxima perversión de instintos naturales, provocada ya por aberraciones de una educación torcida.» (1.74). Según Germán Suárez Blanco 8 , este personaje está configurado como un sapo; lo vemos, por ejemplo, cuando escupe desde la torre, pues el sapo, en la creencia popular, es peligroso por sus salivazos, con los que puede dejar ciego a quien se le queda mirando, como hará Ana. Su retorcida repugnancia, por otro lado, tendrá su mejor exponente en la última página de la obra, en la que comprobamos que Clarín se resiste a despojar de ese ingrediente erótico a sus personajes. El beso que da a la Regenta por curiosidad, ese «deseo miserable, una perversión de la perversión de su lascivia» (30.986), cierra la obra y cumple la profecía inicial. Si Celedonio tendía a la perversión de lo natural, digamos, a la homosexualidad -si se puede decir que la heterosexualidad es el instinto natural por antonomasia- ahora siente deseos de pervertir esa tendencia ya pervertida, es decir, de besar a una persona del sexo opuesto. El terror y el erotismo cierran la obra de un modo magistral. Por supuesto, se trata de un aspecto del erotismo que no deja de ser, como veíamos con Petronila, repugnante, viscoso, horrible. Esa perversión de la perversión es, como dice Kronik, «la valorización estética de la fealdad humana, social y moral que La Regenta se esfuerza por reproducir»?.

¿Acaso se hubieran podido ensamblar mejor en un solo personaje erotismo y terror? Tanto Petronila como Celedonio sintetizan perfectamente esa perturbación que sufre el lector ante un orden desplazado, ante algo que no responde a lo normal, algo que no es lo que se espera que ocurra. Eso es lo grotesco, la parodia, la ironía, la caricatura que inundan la obra. Es el «estímulo a la risa en la cual se siente algo inquietante» ${ }^{10}$, y es precisamente esa risa amarga, esa inquietud la que nos transmite la sensación de terror.

Algo parecido a lo que siente el Magistral cuando se entera de que, finalmente, Ana ha sucumbido a Mesía: «Sintió una carcajada de Lucifer dentro del cuerpo; sí, el diablo se le había reído en las entrañas...» (29.922). Un diablo que se ríe de él, que se ríe de su sotana, de su impotencia. Un diablo representado por Celedonio al final de la novela y por otros elementos a lo largo del texto que precede; en este caso ese diablo es lo que lleva dentro Fermín. Para Ana, sin embargo, Mesía será la representación del diablo, la tentación contra la que tiene que luchar constantemente, oponiéndose, además, a Visita, quien «no quería renunciar al placer de ver a su amiga caer donde ella había caído» (16.512). En este caso el diablo representa el erotismo contra el que Ana lucha, mientras que antes, en el

\footnotetext{
7 Ibid.; p. 520.

8 Cf. Germán Suárez Blanco (1987): «Personajes malditos en La Regenta». En: «Clarín»y La Regenta en su tiempo. Actas del simposio internacional. Oviedo: Universidad, p. 770.

9 Kronik, op. cit., p. 524.

${ }^{10}$ Ibid., p. 518.
} 
caso de Celedonio por ejemplo, podría representar perfectamente el terror. De nuevo esta inseparable imbricación entre ambos elementos.

Recapitulemos. Hemos visto que doña Paula suele aparecer como símbolo del terror y que estos dos personajes, Celedonio y Petronila, se caracterizan por su presencia perturbadora, por la dimensión grotesca que pivota sobre ellos pero que inunda toda la obra. Vamos a ver ahora a esos otros personajes perversos, que llevan el diablo dentro y que aparecen indistintamente en situaciones terroríficas y eróticas. Para hacernos una idea, bastará con sistematizar las características de Petra, la criada de Ana, y del Magistral, como representantes de dicho prototipo.

Empecemos por Petra, quien al principio de la novela no resulta especialmente repugnante, aunque sí tiene ese matiz extraño y oscuro que irá en aumento hasta llegar a esa sensación final que provoca la repulsión y el escalofrío del lector. Lo mismo ocurre con el Magistral, protagonista de intensos momentos eróticos, pero sumido siempre en una cierta oscuridad, que le rodea como un aura misteriosa. Esa es la razón por la que resultan -la «rubia lúbrica» y el misterioso Magistral- el gozne esencial, el lugar de encuentro de esos dos motivos. Veamos la primera aparición de la criada de Ana Ozores: «entraba Petra, su doncella, asustada, casi desnuda...» (3.141); más tarde se la describe así: «Su hermosura podía excitar deseos, pero difícilmente producir simpatías [...]. Era buena para todo, y se aburría en casa de Quintanar, donde no había aventuras ni propias ni ajenas.» (9.291).

Ya desde el principio queda claro que se trata de un personaje perverso donde los haya, deseoso del mal del prójimo. Su presencia es siempre inquietante; ávida de malas acciones, espera siempre el momento de descubrir los trapos sucios de cada casa. Es fácil de ilustrarlo textualmente cuando leemos cosas como esa «delicia morbosa» con la que «la rubia lúbrica olfateaba la deshonra de aquel hogar» (10.338). Quizá sobre aclarar la mezcla de perversidad y erotismo que este personaje encierra en afirmaciones como esta. Por supuesto, será ella quien, al final de la novela, lleve las riendas del juego; Clarín pone el destino de todos los protagonistas en manos de esta rubia lúbrica, maquiavélica y terrible. ¿Qué final se puede esperar, pues, si todo está en su poder? Sólo hay un final posible, y el autor lo sabía perfectamente.

Don Fermín de Pas es uno de los protagonistas de la novela, el primero que aparece, y se le describe así:

Los ojos del Magistral, verdes [...], de en medio de aquella crasitud pegajosa salía un resplandor punzante, que era una sorpresa desagradable, como una aguja en una almohada de plumas [...]. Aquella nariz era la obra muerta en aquel rostro todo expresión [...]. Labios largos y delgados, finos, pálidos [...]. Expresión de prudencia de la que toca en cobarde hipocresía y anuncia frío y calculador egoísmo [...], un cuello de atleta [...] hubiera sido en su aldea [...] el mozo de más partido... (1.75).

Asentada queda desde su primera aparición la tan lograda mezcla de sensualidad y terror con que se construye a este personaje. Vemos esos ojos verdes, bellos, pero tradicionalmente relacionados con el mal ${ }^{11}$, que además guardan una sorpresa desagradable,

${ }^{11}$ Cf. Julio Rodríguez Puértolas (2002): «Clarín: literatura y modernidad». En: Congreso Internacional Leopoldo Alas «Clarín» en su centenario (1901-2001). Espejo de una época. Pilar García Pinacho e Isabel Pérez Cuenca (eds.). Madrid: Universidad San Pablo CEU, p. 131. 
tan desagradable como una aguja dentro de una almohada de plumas. La mezcla ambigua de lo inquietante y lo erótico, alcanza en este personaje su mejor expresión.

Nos detendremos ahora en un par de escenas para mostrar esa doble cara de la moneda erotismo-terror que representa el Magistral. Recordemos, por ejemplo, la tan significativa en que se encuentra él solo frente al espejo: «Estaba desnudo de medio cuerpo arriba. El cuello robusto parecía más fuerte ahora [...]. Los brazos de vello negro ensortijado, lo mismo que el pecho alto y fuerte, parecían de un atleta.» (9.358). Se le compara después con Hércules, metáfora que le perseguirá durante toda la novela. A pesar de esta sensualidad manifiesta, unas líneas más abajo vemos que «miraba con tristeza sus músculos de acero, de una fuerza inútil», algo que inevitablemente recuerda a esa «hermosura inútil» que flagelará Ana para intentar acallar la sensualidad que la desborda, para desviar la carga sensual hacia la vertiente mística y alejarse de la puramente erótica (23.757). Afinidad entre los dos protagonistas que no deja de ser llamativa. Importantes resultan también las escenas en que ambos se encuentran solos, las chispas que salen de sus ojos, aunque cada uno aliente íntimas expectativas muy diferentes. En el Magistral esta sensualidad se convertirá en trágica por la sotana en donde se oculta y que le esconde y le reprime: «En cuanto se abrochó el alzacuello, el Magistral volvió a ser la imagen de la mansedumbre cristiana [...] seguía siendo esbelto, pero no formidable. Se parecía un poco a su querida torre de la catedral, también robusta [...] pero de piedra» (9.358).

El terror aquí es consecuencia de esa sotana que actúa como cadena y que al reprimir los verdaderos deseos de su poseedor, consigue que este saque su lado más terrible, más abominable. No hay más que recordar la escena en que don Fermín y Quintanar van a buscar a los muchachos al bosque, en medio de una tormenta y de un ambiente tenebroso: «Arrastrando con dificultad el balandrán empapado que pesaba arrobas, la sotana desgarrada a trechos y cubierta de lodo y telarañas mojadas.» (28.874). Esta vez son las telarañas el símbolo del terror, de lo inquietante, de lo asqueroso e inevitable, la materia que no deja avanzar al cura en su ansiosa búsqueda, al igual que la sotana, comparada en muchas ocasiones de la novela con unas cadenas que lo aherrojan.

Ana Ozores y Fermín de Pas son personajes, en su erotismo frustrado, profundamente afines; veamos cómo cada uno a su manera se lamenta de su situación en el mundo, de la vida que llevan, sujeta a las constantes represiones de su sensualidad... Primero la Regenta:

Ella se moría de hastío. Tenía veintisiete años, la juventud huía [...] y no había gozado una sola vez esas delicias del amor de que hablan todos [...]. El amor es lo único que vale la pena de vivir, había ella oído y leído muchas veces [...]. Y recordaba entre avergonzada y furiosa que su luna de miel había sido [...] un sarcasmo en el fondo. (10.327).

$\mathrm{Su}$ vida entera es un «presidio de castidad» tan trágico, que es fácil entender el desenlace final de la novela y las razones por las que elige a ese «gallito» inculto y vanidoso como amante... Veamos ahora el hastío del Magistral:

Él necesitaba un amor más blando que el de doña Paula [...]. Le faltaba compañía en el mundo; era indudable [...]. De repente se acordó de sus treinta y cinco años, de la vida estéril que había tenido [...]. Se tuvo una lástima tiernísima [...], lloraba para dentro, mirando la luna a través de unas telarañas de hilos de lágrimas... (15.493-4). 
De nuevo las telarañas... Es esa intelectualidad, de la que carecen los demás personajes de Vetusta, propia únicamente de ellos, la que causa el nihilismo y el pesimismo de los dos protagonistas... Es claro que cuanto más sabe uno, menos satisfecho está con lo que tiene, más anhela, más desea... Clarín, con esta confundida dualidad, nos pone ante la auténtica muralla que los separa, una muralla hecha de tela, la sotana... El destino y los anhelos de ambos, la satisfacción de una sexualidad reprimida durante toda la vida, quedan lastrados por la condición de clérigo de don Fermín; por eso, cada uno tiende a una solución diferente: la Regenta hacia el sexo con otro, Álvaro Mesía, un donjuán de pueblo, y el Magistral hacia los celos, la ira, la furia y el terror...

En Ana Ozores no hay rastro alguno de perversidad, no vemos en ella la maldad de Visita, por ejemplo, con sus dejos perversos y sus ansias de destrucción de lo virtuoso... Ana no es así, ella es un personaje aparte, sólo busca la felicidad propia, la tranquilidad interior, la plenitud... Esto, por supuesto, no quiere decir que acierte con sus decisiones, de hecho todo el desenlace trágico será causado por sus actos, pero sin mala intención por su parte... Sin embargo, la inocencia de Ana se ve constantemente atacada por los demás personajes, que representan una maldad, por lo común, cutre y terrible, que busca un placer insano en la desgracia ajena...

Ella es el blanco erótico de la novela y el blanco del sórdido terror que la atraviesa... Ana acaba de confesar con el Magistral y está tan pletórica que propone a Petra ir a dar un paseo por el campo. Llegan a la fuente de Mari-Pepa, de repente Ana se ve rodeada por una naturaleza ideal y empieza a recordar las dulces palabras del Magistral, quien la ha embaucado con su brillante elocuencia y con metáforas que no dejan de ser eróticas; por ejemplo la del río, «ella se había visto con su traje de baño, sin mangas [...] y en la orilla estaba el Magistral con su roquete blanquísimo» (9.296). Está tremendamente cegada por la maestría de don Fermín, le idolatra, piensa en él como en un ejemplo a seguir. Pero, de pronto,

...volvió a la realidad. Todo quedó en la sombra [...]. La sombra y el frío fueron repentinos. [...]. Un sapo en cuclillas miraba a la Regenta encaramado en una raíz gruesa [...], Ana dio un grito, tuvo miedo. Se le figuró que aquel sapo había estado oyéndola pensar y se burlaba de sus ilusiones (9.301).

Escena terrible donde las haya, en donde el sapo aparece como símbolo de lo oscuro, de lo terrible, con su viscosa realidad... Volvemos a ese juego con los sentidos, siempre relacionado con la muerte, e incluso con anormalidades de orden sexual; la aparición de este animal no deja indiferente al lector, que se cuestiona el porqué de su repentina presencia. Este sapo se burla de Ana, de sus ilusiones, como antes el Magistral sentía las carcajadas de Lucifer dentro: de nuevo el paralelismo entre los protagonistas... Sin embargo, en este caso el sapo representa la cara oculta del clérigo don Fermín, eso que Ana todavía no conoce. Es como la metáfora del interior de los personajes, incluso, más adelante, de la misma Ana... Estamos ante el mundo en putrefacción, un mundo lleno de tabúes, con dos caras, la pública y la privada, la moral aparente y la inmoralidad real, las sonrisas falsas y las depravaciones palpables...

Además, es interesante notar el grave contraste ${ }^{12}$ entre erotismo y terror que, unas líneas más abajo, se da entre la aterrorizada Ana y su lúbrica criada, Petra, quien viene de

${ }^{12}$ Sigo aquí a Gullón, op. cit., p. 334. 
ver a su primo el molinero. La primera estaba ensimismada en las palabras del Magistral y la segunda ha ido a disfrutar de placeres no precisamente místicos. Por ello, ha de aparecer la naturaleza, tomando la forma de un sapo, para que Ana sienta frío y sus sentidos despierten. Esos sentidos -cauces de lo erótico- que al final de la novela ganarán la lucha contra la impostura espiritual... La mirada del sapo simboliza, para Gullón, «la fuerza de la primera naturaleza, es una mirada viscosa del hombre que Ana siente desde niña con el amante de la institutriz, hasta el Magistral, que la busca desde la torre de la catedral» ${ }^{13}$.

La escena del sapo representaría, pues, el paso del erotismo al terror, de la sensualidad ilusionada a una oscura inquietud... La Regenta piensa en el Magistral con voluptuosidad inocente y de repente se encuentra sumida en una oscuridad aterradora. Algo parecido ocurrirá en otros momentos de la obra, sobre todo cuando Ana piensa en don Álvaro Mesía y acto seguido un escalofrío le recorre el cuerpo. También vemos esto en el Magistral, que va a la celebración del santo de Paquito Vegallana, y con la escena del columpio queda don Fermín como símbolo de lo erótico, de la fuerza masculina. Pero luego, a pesar de que decide no ir al Vivero a seguir con la celebración, se queda en el Espolón esperando que lleguen las carrozas hasta que se hace de noche:

Quedó solo don Fermín con un murciélago que volaba yendo y viniendo sobre su cabeza, casi tocándole con las alas diabólicas [...], cada vez que veía al animalucho encima sentía un poco de frío en las raíces del pelo [...]. La brisa se dormía y el silbido de los sapos llenaba el campo de perezosa tristeza... (14.470).

De nuevo todo ese imaginario terrorífico propio de la novela gótica, del que se vale el autor para equilibrar la balanza y para inquietar más y más al lector. Un murciélago diabólico que sobrevuela a don Fermín, y que incluso se podría identificar con él mismo, por esas alas que recuerdan a su sotana, esos escalofríos en las raíces del pelo, los sapos lejanos... Todo apunta a ello, a esa viscosidad podrida que en la novela suele identificarse con el «elemento clerical», que diría el poeta Cármenes.

En relación con el Magistral, cabe destacar también la parte en que va al Vivero a visitar a los Quintanar, que celebran comidas muy frecuentemente, y, como llega tarde, Petra le conduce por el bosque para buscar a la comitiva. Paran a descansar cerca de una cabaña de leñador que hay en la colina y acaban entrando en ella; estamos ante uno de los momentos más eróticos de toda la novela. Pero más tarde, después de comer, comienza a llover y el Magistral obliga a don Víctor a ir en busca de Ana. Esta escena es una de las más terroríficas protagonizadas por don Fermín, le vemos furioso, «ciego», con «el corazón, que reventaba de celos» (28.874-5) y muy violento, «dispuesto a matar si era preciso» (ibid.) y sobre todo: bajo la lluvia, rodeado de telarañas, con la sotana empapada y hecha jirones. Queda claro el gran contraste entre ambas escenas, una de las más eróticas seguida inmediatamente de una de las más terroríficas.

En cuanto a Ana, la vemos en un momento dado fantaseando con Mesía, y acto seguido entra en el despacho de su marido a oscuras, quedando atrapada por esas «tenazas inflexibles que oprimían la carne con fuerza» (10.323). De nuevo, un momento erótico seguido de uno terrorífico. Sin mencionar el hecho de que Ana se vea atrapada en la oscuridad, impotente y abandonada en su propia casa, y sólo tenga a Petra, criada perver-

${ }^{13}$ Ibid. 
sa, para ayudarla. Más tarde, cuando sale al jardín llena de ira y de vergüenza, se nos presenta un paisaje poco menos que abrumador: «Vetusta quedó envuelta en la sombra. La torre de la catedral [...] ya no fue más que un fantasma puntiagudo; más sombra en la sombra.» (10.329). Acto seguido aparece un bulto en medio de esa oscuridad: don Álvaro Mesía ha ido a rondar a Ana y esta, al sentirlo, huye. Como indica Víctor Fuentes ${ }^{14}$, esta sombra de la catedral aparece «como personificación de la parte instintiva», como una «invocación inconsciente del deseo de Ana para que aparezca Álvaro». Algo parecido a lo que decíamos del llamamiento a los sentidos mediante la grotesca presencia del sapo. Existe una indudable trama erótico-terrorífica, en todas estas escenas, que apunta a una de las claves interpretativas más centrales de esta novela. Y es la religión uno de los elementos más típicamente terroríficos dentro de la misma...

Ya vimos al maquiavélico Glocester, pero ahora detengámonos en otros aspectos... La torre de la catedral, por ejemplo, siempre presente, aparece como dominadora de Vetusta, por encima de todo, oscura, sombría, triunfante. Por ejemplo, en el extraordinario capítulo en que se nos describe la lluvia en Vetusta; todo aparece disuelto bajo esa lluvia excepto la torre de la catedral, que «aparecía a lo lejos [...] como un mástil sumergido» (18.575), es la única que sobrevive, el mástil de la torre quedará siempre aunque la ciudad se hunda, será la única que siga ahí, poderosa, inextinguible. Vimos que era la «querida torre» de don Fermín, pues este aparece ya desde el primer capítulo como extensión o personificación de esa torre y de ese poder sobre el pueblo. Pero poco a poco, y gracias a la destrucción de Ana, don Fermín irá perdiendo poder. También su madre, quien al controlar al mismo Fermín controla a toda Vetusta, aparece en algunos momentos con la forma de esa torre, recordemos a ese «fantasma negro, largo y anguloso» en lo alto de la escalera, que bien podría ser la descripción de la propia torre de la catedral.

En un momento dado, se encuentra Fermín reflexionando sobre Ana y la manera en que mejor podría controlarla, y piensa: «¿Cómo dominarla si quería sublevarse? No había modo. ¿Por el terror de la religión? Patarata. La religión para aquella señora nunca podía ser el terror.» (17.554). Así, aparece explícitamente el uso de la religión como medio para captar y manipular a la gente, ese temor de Dios usado para intereses propios, el terror al más allá. En definitiva, la religión como terror es una idea que ronda toda la novela como los murciélagos aquellos sobrevolaban la cabeza del Magistral...

Recordemos el famoso sueño de Ana, que en el capítulo anterior ha ido con el Magistral por primera vez a casa de doña Petronila Rianzares. Allí el ambiente no es precisamente espiritual, para empezar está ese «gato blanco, gordo, de cola opulenta y de curvas elegantes» (18.595) que ronda a los personajes, símbolo tremendamente erótico; también el ambiente, que «estaba ligeramente perfumado»-de nuevo esa insistencia en los olores, que nos introducen en una situación tan sensual como profana-; además, como indica V. Fuentes ${ }^{15}$, esta casa «tiene mucho de cuarto de citas», lo cual nos sitúa ya de un modo irremediable ante una escena erótica donde las haya. Con este escenario de fondo, Ana se entrega al poder del Magistral, para gran alegría de este, y al final del capítulo vemos que «don Fermín, sin pensar en contenerse, cogió una mano de la Regenta» y «la oprimió entre las suyas sacudiéndola» (18.597-8). De pronto entra doña Petronila y es entonces cuando le da ese beso frío, solemne, del que ya hemos hablado. Acaba así el capítulo y comienza el siguiente, con la terrible enfermedad de Ana y esos «sueños poblados de

\footnotetext{
${ }^{14}$ En la nota 17 a este mismo pasaje de la edición que manejamos.

${ }^{15}$ Nota 21 a este pasaje.
} 
larvas» (19.599) de los que queríamos hablar. A través de esa convalecencia, la protagonista va recordando el pasado invierno y las causas de su enfermedad... La narración de los hechos se ve mezclada con sus sueños, pensamientos y reacciones... Así, después de la escena erótica que hemos descrito, nos adentramos en un capítulo lleno de enfermedad, confusión, muerte, terror:

Ana tuvo aquellas noches sueños horribles [...]. Parecía sentir todavía el roce de los fantasmas groseros y cínicos, cubiertos de peste; oler hediondas emanaciones de sus podredumbres, respirar en la atmósfera fría, casi viscosa, de los subterráneos en que el delirio la aprisionaba... (19.611).

El pasaje es muy extenso y en él vemos ya muchos de esos fantasmas groseros -que recuerdan a la fantasmagórica torre de la catedral, o a don Fermín y su madre- que huelen a podredumbre; los aromas eróticos y sensuales se transforman ahora en algo podrido y estancado (una vez más). Además, el ambiente, antes perfumado y suave, es aquí frío y viscoso como el sapo, como la religión misma, como muchos de los personajes que pueblan la novela. Vemos después «andrajosos vestiglos» que se ríen «a carcajadas» (de nuevo las carcajadas diabólicas de la locura, de Lucifer, de la maldad y del horror). Carcajadas deformadas que nada tienen que ver con esa risa característica de Visitación... ¿o quizá sí? Más tarde se nos habla de «larvas asquerosas», con «casullas de oro». Lo religioso como símbolo del terror queda más que patente, y por si fuera poco, hay unos «manteos que al tocarlos eran como alas de murciélago» (19.612). Ese murciélago que hace poco rondaba la cabeza del Magistral aparece aquí, y las alas, también mencionadas, son comparadas con un manteo: puede ser cualquier manteo, o puede ser el de don Fermín. No hay un pasaje más terrorífico en toda la novela y resulta significativo que tenga que ver con el mundo de los sueños, del inconsciente de Anita, pues ahí dentro es donde están todos los problemas... Por eso vemos que la obligan esos vestiglos a pasar por un agujero angosto, que bien podría ser Vetusta, que se ríe de ella a carcajadas y juega con su persona como le viene en gana. Ya hemos visto que el Magistral aparece indirectamente y por lo tanto, este sueño reúne todas las preocupaciones de la Regenta, todos sus miedos, sus terrores, sus obsesiones...

El terror, pues, es, una y otra vez, la otra cara de la pulsión erótica, ya sea ilusa e inocente, ya sea perversa o retorcida, da igual; es la consecuencia invariable de la pasión desenfrenada... Una escena erótica, en efecto, va siempre seguida por una terrorífica, pero continuemos...

\section{Cómo se manifiesta la sexualidad}

Parece claro que Clarín, en esta novela, describe a sus personajes, muchas veces, en función de sus tendencias sexuales... Y ello está, según creo, íntimamente relacionado con el binomio expuesto erotismo/terror. Parece como si Clarín se hubiese propuesto retratar a una sociedad llena de limitaciones, represiones, anormalidades, elementos grotescos e inmorales...

Tenemos personajes masculinos afeminados, como Celedonio, a quien ya hemos tratado, o como don Anacleto, un familiar del obispo que apenas aparece dos veces en la novela, una de ellas mencionado por el mismo Celedonio, quien le imita, y otra en la antesala del obispo, jugando al tute, y se nos presenta como «hermoso, rubio, de movi- 
mientos suaves y ondulantes [...], perfumado» (12.385) O ese «deseo vago de ser hombre» que le invade a Obdulia Fandiño cuando ve desfilar a Ana descalza en la procesión, en una escena con claros tintes lésbicos, al igual que la ya mencionada descripción que hace Visita de su amiga Ana: «Ella es hermosa, Alvarín, hermosa, hermosa [...]. ¡Cómo se ríe cuando está en el ataque! Tiene los ojos llenos de lágrimas, y en la boca unos pliegues tentadores, y dentro de la remonísima garganta suenan unos ruidos, unos ayes...» (8.284). O qué decir de doña Petronila... En cualquier caso, no resulta raro en la novela el que también las mujeres, como los hombres, se sientan atraídas por la Regenta...

Y qué decir del adulterio, consustancial a la vida de los habitantes de la novela... Ya sabemos que ningún personaje se salva de ser infiel; ni siquiera el propio don Víctor, dentro de su impotencia, puede jactarse de ser inocente, o el marqués de Vegallana, jefe del partido conservador, que va dejando aldeanas embarazadas por todos los pueblos de las afueras de Vetusta... Es interesante marcar la ironía con que trata el autor este cinismo cuando el marqués tacha de «nauseabundo» el escándalo del duelo: «esto lo dijo el marqués de Vegallana, que tenía en la aldea todos sus hijos ilegítimos» (30.976). Lo que deja a las claras la doble moral adúltera retratada en la novela.

Nos parece, además, imprescindible mencionar el fetichismo, es decir, elementos, animados o inanimados, que son, por unas razones o por otras, símbolos de lo erótico, adorados y tratados como más de lo que son. Válganos como ejemplo el guante que se olvida el Magistral en casa de los Ozores, que encuentra Frígilis y luego es arrebatado por Petra y guardado con gran celo. También el crucifijo que le regala don Fermín a Ana y que ésta «sacó del seno [...] y sobre el marfil caliente y amarillo puso los labios» (20.668): es objeto de culto erótico y actúa como fetiche para el lector... No olvidemos que Ana lo lleva escondido en el pecho y al besarlo sabemos que está caliente por haber estado ahí. Pero, en cualquier caso, quizá el ejemplo más claro de fetichismo lo tengamos en la procesión, en los pies de Ana, descalzos, que son objeto de atención de toda Vetusta... Nunca los «desnudos hombros», los «brazos de marfil», la «espalda de curvas vertiginosas» de Obdulia Fandiño fueron tan admirados como los «dos pies descalzos que apenas se podían entrever de vez en cuando debajo del terciopelo morado de la nazarena» (26.825).

O ese ligero tono de pedofilia que da Clarín al episodio del catecismo de las niñas de Vetusta... Ya hemos mencionado a don Fermín y las rosas que come de camino a la catedral, donde le aguardan esas «niñas de siete a catorce años» (21.679), a quienes los catequistas

reprenden [...] con palabras de miel y sonrisas paternales y se meten entre banco y banco mezclando lo negro de sus manteos [...] con las faldas cortas de colores vivos, y el blanco nieve de las medias que ciñen pantorrillas de mujer a las que el traje largo no dio todavía patente de tales. (21.680).

O el sadomasoquismo de Petra, que, según Suárez Blanco ${ }^{16}$, es uno de los personajes malditos más importantes, pues sigue al pie de la letra la filosofía del marqués de Sade: «El mayor dolor de los demás cuenta siempre menos que mi deleite. No importa si debo comprar el goce más mínimo con una inaudita acumulación de maldades.» Su placer, en

${ }^{16}$ Usamos a continuación un texto de Sade citado por Suárez Blanco a través de la obra Lautrémont et Sade de Maurice Blanchot; $c f$. nota 8 del artículo de Suárez Blanco que manejamos; p. 775. 
efecto, está en función del sufrimiento de los demás... Ella desea al Magistral y quiere ver hundida a la Regenta, su señora, por envidia y por rencor. Disfruta sabiendo que el desenlace trágico de la historia está en sus manos y juega con todos los personajes, los manipula, incluso a Fermín y a Mesía, aun cuando éstos creen tenerla a su disposición. También Visita es un personaje sádico en este sentido, pues, como hemos visto, disfruta con la caída de Ana en las redes de Álvaro, y si no, baste con mencionar ese: «Quería ver aquel armiño en el lodo» (8.282).

Resulta interesantísimo recordar la posibilidad de que Clarín hubiese leído a Sade... Esta tesis la sostiene Paula Préneron ${ }^{17}$ al hablar del asombroso parecido que se da entre la dinámica de la obra Justina o los infortunios de la virtud ${ }^{18}$ y la de La Regenta... Tanto Justina como Ana quieren ser buenas y virtuosas, elevar su espíritu, y sin embargo ambas son constantemente vencidas por la realidad, por la materia. Aunque Préneron no ahonda en las claras diferencias que existen... Para empezar, Ana tiene un claro instinto sexual que es el que la lleva a caer definitivamente en lo carnal; sin embargo, Justina nunca siente un deseo sexual claro, siempre se ve obligada por los demás a hacer lo que hace... Por lo tanto, el gran dilema que sustenta la obra de Clarín no aparece en la de Sade, pues Justina no decide nada, no se debate entre lo espiritual y lo carnal, ella solamente busca lo espiritual y se ve arrastrada irremediablemente a lo carnal... Sade nos demuestra mediante su derrota lo imposible que resulta intentar ser bueno en este mundo en que vivimos, y eso quizá es también lo que expone Clarín, pero éste no se conforma con tal reconocimiento; el marqués sólo nos invita a disfrutar mientras se pueda... Filosofías muy dispares, como se ve... Además, la expresión de una sexualidad tan explícita y brutal, característica del autor francés, resulta poco menos que inconcebible en nuestra novela... En lo que sí estoy de acuerdo con Préneron es en que tanto para Ana como para Justina, «la realidad, que ambas pretenden negar, se encarga de desbaratar todo ideal espiritual, y les prueba una y otra vez que son sólo un elemento más de la naturaleza» ${ }^{19}$. Parece evidente el trasfondo sadomasoquista en diversos personajes y escenas de la novela, por ejemplo en el famoso episodio de autoflagelación de Ana... Asimismo vemos que la propia protagonista se regodea en mantener la tentación, prefiere sufrir esa tentación antes que rechazar directamente a Mesía: «La tentación era suya, su único placer. ¡Bastante hacía con no dejarse vencer, pero quería dejarse tentar!» (9.315). Es evidente el motivo masoquista que forma parte de su personalidad. También Mesía es un personaje con tintes sadomasoquistas muy concretos: esas luchas, que él mismo narra, con una aldeana llamada Ramona, a quien viola, o las confesiones que obliga a hacer a sus amantes: «En los momentos de pasión desenfrenada a que él arrastraba a la hembra siempre que podía, para hacerla degradarse y gozar él de veras con algo nuevo, obligaba a su víctima a desnudar el alma en su presencia...» (13.433). En esta mezcla de lo sagrado y lo sexual, tan típica de Sade, muchos personajes encuentran un gozo infinito. Hay una escena de burla directa de la eucaristía protagonizada nada más y nada menos que por el Magistral: cuando le da los bizcochos mojados en chocolate a Teresina, su criada, «y así todas las mañanas» (21.706). Transparente ironía el retratar esta costumbre con la rutina propia

\footnotetext{
${ }^{17}$ Cf. Paula Préneron Vinche (1996): «La Regenta: condena del libertinaje». En: El influjo de Sade en Flaubert y «Clarín». Alicante: Universidad, pp. 161-196.

${ }^{18}$ Cf. Marqués de Sade (2003): Justina o los infortunios de la virtud. Isabel Brouard (ed.). Madrid: Cátedra.

${ }^{19}$ Préneron, op. cit., p. 172.
} 
del culto religioso, y sobre todo, protagonizada por un clérigo ${ }^{20}$. Por supuesto, en esta imbricación morbosa de lo religioso y lo sexual no hemos de pasar por alto los amores del Magistral con sus doncellas, proporcionadas además por su propia madre, como sabemos.

Existe otra profanación de los hábitos religiosos muy bien señalada por Valis ${ }^{21}$. Ocurre en la escena final, «repleta de alusiones eucarísticas», en cuanto que Celedonio, monaguillo de la catedral, hace de «hostiero» depositando ese asqueroso beso en la boca de Ana, que es la que recibe la «sagrada forma». Este episodio final sugiere, según Valis, «la conjunción de dos mundos distintos que, aunque ligados entre sí, no pueden reconciliarse ${ }^{22}$. Dos mundos radicalmente distintos y opuestos, pero tan íntimamente unidos en la historia de España, que le resulta imposible a un autor como Clarín no enlazarlos...

Recordemos las escenas de don Saturnino y Obdulia en la catedral, con esos juegos morbosos, más morbosos todavía por situarse en un lugar religioso. $\mathrm{O}$ ese olor ya mencionado del Magistral, mezcla de «incienso espiritual» con una sensualidad propia del gato de doña Petronila. Recordemos también la escena de la catedral en Nochebuena y esa especie de orgía que se forma con todo el pueblo junto y frotándose, que podría recordar a una escena del mismo Sade... Y por supuesto, el crucifijo, señalado como fetiche, actúa también como enlace entre lo que representa -la religión- y donde está situado - el pecho de Ana, tan codiciado por toda Vetusta.

La «corrupción» de los habitantes de Vetusta no tendría mayor trascendencia si todos la aceptasen tal como es, como fruto natural de las pulsiones eróticas; sin embargo, con una hipocresía llevada hasta extremos «aterradores» y perversos, todos se jactan de actuar «moralmente» y es eso precisamente lo que convierte a sus actos en actos degradados, horribles y perversos... Señalemos, por último y siguiendo las palabras de Fuentes $^{23}$, que «la inquietud religiosa», tan ligada al terror, y «el misticismo vinculado al erotismo» son grandes constantes de la época decadentista y, por supuesto, son las que sustentan nuestra obra. En efecto, el juego entre erotismo y terror es uno de los pilares de La Regenta y eso hemos intentado demostrar; dejemos a Fermín de Pas la última palabra, cuando furioso e iracundo escribe a Ana una carta que luego romperá y que contiene estas palabras:

Yo soy tu esposo; me lo has prometido de cien maneras; [...]. Toda eres mía, sobre todo porque te quiero como tu miserable vetustense y el aragonés no te pueden querer [...]. Las olvidaste... por un cacho de carne fofa, relamida por todas las mujeres malas del pueblo... $(30.950)^{24}$.

\footnotetext{
${ }^{20}$ He seguido hasta aquí, con variaciones y ampliaciones mías, la obra de Préneron, op. cit., para desarrollar el tema del sadomasoquismo.

${ }^{21}$ Noël M. Valis, op. cit., p. 798.

${ }^{22}$ Ibid., p. 799.

${ }^{23}$ Introducción a la edición señalada de La Regenta de Víctor Fuentes, p. 18.

${ }^{24}$ La negrita es mía.
} 


\section{BIBLIOGRAFÍA}

Alas, Clarín, Leopoldo (1999): La Regenta. Víctor Fuentes (ed.). Madrid: Akal, 1999.

Blanco Aguinaga, C.; Rodríguez Puértolas, J.; Zavala, I. M. (1986): Historia social de la literatura española (en lengua castellana), 2. Madrid: Castalia, 129-218.

Gullón, Germán (2002): «La mirada masculina y la conciencia en La Regenta». En: Leopoldo Alas «Clarín». Actas del simposio internacional (Barcelona, abril de 2001). Antonio Vilanova y Adolfo Sotelo Vázquez (eds.). Barcelona: Universitat, 325-36.

Kronik, John W. (1987): «El beso del sapo: configuraciones grotescas en La Regenta». En: «Clarín» $y$ La Regenta en su tiempo. Actas del simposio internacional. Oviedo: Universidad, 517-24.

Préneron Vinche, Paula (1996): El influjo de Sade en Flaubert y «Clarín». Alicante: Universidad.

Quiroga, Horacio (1989): «El almohadón de pluma». En: De los perseguidos, de amor, de locura y de muerte. Madrid: Aguilar, 70-76.

Rodríguez Puértolas, Julio (2002): «Clarín: literatura y modernidad». En: Congreso internacional Leopoldo Alas «Clarín» en su centenario (1901-2001). Espejo de una época. Pilar García Pinacho e Isabel Pérez Cuenca (eds.). Madrid: Universidad San Pablo CEU, 121-146.

Sade, Marqués de (2003): Justina o los infortunios de la virtud. Isabel Brouard (ed.). Madrid: Cátedra.

Suárez Blanco, Germán (1987): «Personajes malditos en La Regenta». En: «Clarín» y La Regenta en su tiempo. Actas del simposio internacional. Oviedo: Universidad, 767-77.

Valis, Nöel M. (1987): «Sobre la última frase de La Regenta». En: «Clarín»y La Regenta en su tiempo. Actas del simposio internacional. Oviedo: Universidad, 795-808.

\section{ČUTI IN PERVERTIRANA ČUTNOST ... EROTIČNOST IN GROZA V ROMANU LA REGENTA}

V pričujočem delu poskušamo prikazati dva izmed temeljnih stebrov, na katere se opira La Regenta: erotika in groza. V ta namen smo članek razdelili na tri dele. V prvem so sistematično naštete erotične prvine, ki pronicajo skozi »občutljivost « in čutnost likov. Nato smo poskušali razčleniti način, kako se mnoge izmed teh erotičnih prvin in likov povezujejo s grozljivimi prizori in oblikami vedênja. $\mathrm{V}$ zadnjem delu pa smo poskušali podati kratek, shematičen oris ali vzorčni prikaz spolnih nagnjenj in perverzij, ki so razvite $\mathrm{v}$ romanu. 